\title{
THE STUDENTS' PERCEPTIONS OF THE IMPLEMENTATION OF ICT-SUPPORTED PROJECT BASED LEARNING IN ENGLISH TEACHING
}

\author{
Tri Akhmad Efendi \\ Email: triefendi89@gmail.com \\ Catholic Widya Mandala Surabaya University \\ Surabaya, Indonesia
}

\begin{abstract}
The present study was aimed at investigating the students' perceptions of the implementation of ICT-supported PBL (Project Based Learning) in English teaching at the school under the study. There were three issues covered in this study: (i) the students' perceptions of the benefits of the implementation of ICT-supported PBL to their language skills and components, and (ii) the students' perceptions of the benefits of the implementation of ICT-supported PBL to self-development. This study was a worth-conducting study since it was expected to help teachers see what the students' perceptions of the implementation of ICT-supported PBL. This study was conducted on an intrinsic case study to attempt or emphasis on gaining a deep understanding of the students' perceptions of the implementation of ICT-supported PBL at the school under the study. There were 44 students who were involved in this study. The data collected through the questionnaire and students' reflective report. The findings were overall positive. They perceived self- development and language skills and components enhancement except the students' perceptions of the grammar learning. To add, they felt the teaching and learning activities brought enjoyment in the classroom. There were three factors which led the students' have positive perceptions of ICT-Supported PBL in English teaching; (a) authentic learning situations, (b) student-centered activities, and c) the involvement of ICT.
\end{abstract}

Keywords: self-development, authentic learning, students-centered activities, case study.

\section{INTRODUCTION}

The important of English has attempted many educational institutions and teachers in Indonesia to find out the best ways in teaching English as a foreign language. In addition, many schools are encouraged to set up such an effective English program to develop the 
students' English skills. Moreover, the Education and culture ministry has assigned to schools starting from primary to senior high to be able to lead the students being able to have strong academic skills, critical thinking, teamwork skill, and also proficiency in using technology. Those skills are required in the $21^{\text {st }}$ century learning in hope that the students can make use of their learning to apply knowledge in their daily lives.

In order to be able to achieve that goal, the government has proposed scientific approach in teaching and learning any subjects, including English, in all levels. One of the scientific approaches that the government suggested is Project-Based Learning (PBL). Substantially, the basic concept of PBL is learners learn by doing through the process of exploring, scaffolding, interpreting, negotiating, and creating. In like manner, learning with PBL does not focus on learning about something but it focuses on doing something since PBL is action oriented (Moursund, 2003). Point to overlooked, scientific approach emphasizes the students be able to observe, ask, explore, associate and communicate in the hope that the students will develop their sense of inquiry similarly with the expected outcome in the $21^{\text {st }}$-century learning.

The school under this study is one of the private junior schools in Surabaya which has already implemented PBL for the English subject before it was announced and promoted by the government. This school has been implementing PBL for three years. To add, the PBL has been applied with the help of ICT. The English coordinator mentioned that the students had to deal with some projects during one semester which mainly ICT based. The teacher makes use of the ICT as a part of doing the projects. Most of the projects were done in and outside classroom mostly with the involvement of ICT. Thereupon, they were allowed to use any gadgets in the English classroom to support their learning as well as using school's wi-fi. Correspondingly, the teacher tried to help and interact with the students not only in class but also outside the classroom through emails, social media like BBM, Line, and Edmodo. It makes this school has different English class from other schools. Unlike the conventional teaching and learning where students are portrayed with the exposure of forms and loaded with lots 
of paper exercises. The students at the school under this study do the projects on making video, doing survey, doing interview, and etc. ICT in the English class is not only used as an aid to carrying out the work in the project but also it is a part of the content of the project.

Points to those facts, the research questions are (1) What are the students' perceptions of the benefits of the implementation of ICTsupported PBL to the development of language skills and components? and (2) What are the students' perceptions of the benefits of the implementation of ICT-supported PBL to the self-development?

\section{RESEARCH DESIGN}

This study was an intrinsic case study because the researcher's purpose of conducting this study was to attempt or emphasized on gaining a deep understanding of the students' perceptions of the implementation of ICT-supported PBL at the school under the study. According to Stake (1995), intrinsic case study lies purely in one particular case itself. There is no attempt at all to generalize from the case being studied or compare it to other cases.

Despite the fact that every precaution was taken to carefully prepare and conduct the study, there were still some limitations. First, the number of this study was relatively small. There were only fortyfour students who were sitting in ninth grade as participants. However, as a study with small participants, this study could still provide some indication leads of students' perceptions of the implementation of ICTsupported PBL at the school under the study. Hence, it may also provide some establishment upon further study may be undertaken.

Second, the data were collected through questionnaire. The data on this study was verbal data on the students' responses on the implementation of ICT-supported PBL. Due to some considerations, the researcher also was not allowed to interact and interview the students by the principal. Consequently, the data were limited to the questionnaire and student report.

There were three instruments in this study. The first is the researcher himself as the main instrument who was equipped with the knowledge of the related theories to the topic of this study. The researcher made the items or statements on the questionnaire based on 
the related theories as a mean to analyze the findings. The second instrument was the closed-ended questionnaire. It was left anonymous to make them comfortable. There were fourteen statements in the questionnaire concerning the research questions. Those statements were designed based on the related theory of PBL. In the questionnaire the students had to state their opinions with Likert scale: Strongly Agree (SA), Agree (A), Not sure (NS), Disagree (D), Strongly Disagree (SD). It is shown as follows. The third instrument was the students' report. It was taken from the teacher. The student report was in a form of writing report from the students after they finished every project. There were four parts in the report created by the teacher: narrative report, team evaluation, my contribution, and reflective report. The researcher only focused on the students' reflective report where their opinions on the project were there.

The following is the layout of the reflective report made by teacher which has to be submitted in the last day of the projects:

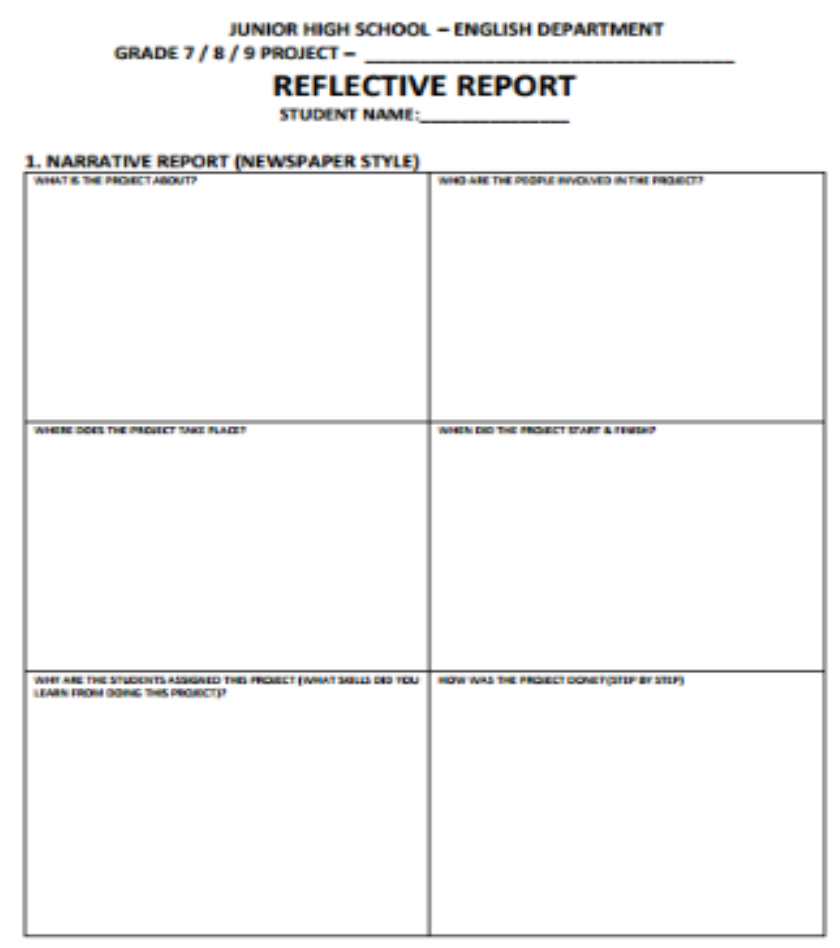



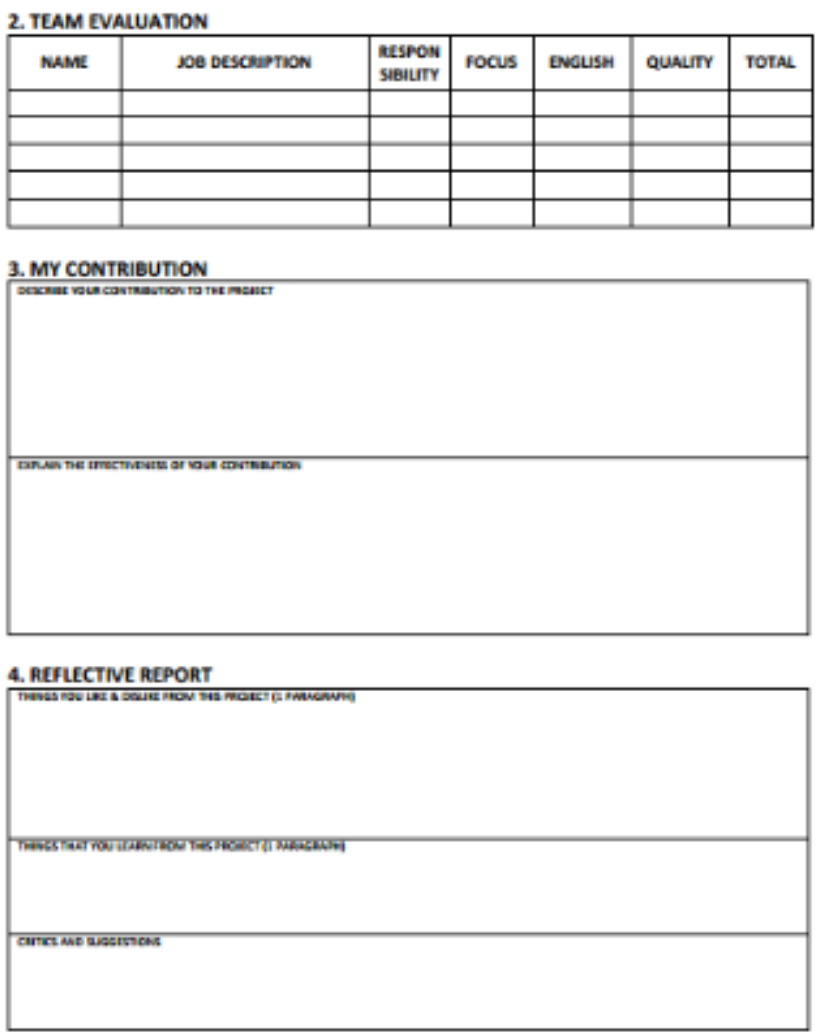

The first was narrative report described six points: a) what the project was about, b) who involved in the project, c) where the project was done, d) when the project started and finished, e) why the project was assigned to the students, and (f) how the step-by- step of the project was done from start to finish. The second part was team evaluation which the students have to evaluate their teammates and themselves. The students had to evaluate their teammates on three aspects: a) responsibility and b) focus, c) English usage. Besides, they also had to evaluate themselves in a column 'My contribution'. In that column, the students had to describe their contribution to their group and they had to explain the significance of their contribution to their group.

The last part of the students' report was a reflective report. In this part the students had to mention and explain: a) the things they 
liked from the project, b) the things they disliked from the project, c) the things they learned from the project, and d) suggestions and critiques for the development of the project.

Regarding the data analysis, the researcher firstly analyzed the results of the questionnaire were based on the Likert scale on the questionnaire. The number of the students who give their opinions on the Likert scale will be counted and it will be put on the percentage. Second, the researcher analyzed the data taken from the students' reflective report on the three projects that they have done. The reflective report will be coded into three: students' positive feedback, negative feedback, and lesson learned from doing the projects. Those codings were taken from the common comment or mostly stated by the students. Then, the data found were summarized into three: (a) self-development and (b) language skills and components enhancement.

\section{FINDINGS}

To figure out (i) the students' perceptions of the benefits of the implementation of ICT-supported PBL to the development of language skills and components and (ii) the students' perceptions of the benefits of the implementation of ICT-supported PBL to the self-development, fourteen statements on the questionnaire were made derived from the review of related theories. Afterwards, the students were asked to give their opinions by responding to the Likert scale if they strongly agreed, agreed, not sure, disagreed, or strongly disagreed with the statements. Then, the result of the responses was counted to see whether the students' opinions on the statements were positive or negative.

Then, the students' reflective reports, which the students had submitted after they had done the projects, were taken from the teacher. Then, the researcher read all the students' comments on that report which then he coded them into three groups: (1) language skill and component enhancement, and (2) self- development.

According to the results of the questionnaire to answer the first research question, the students' opinions regarding the students' English skills and components thought through ICT-supported PBL are positive. They mostly think that the implementation of ICT-supported 
PBL has helped them improving their language skills (listening, speaking, reading and writing). It was because they were learning the four skills while they were developing the projects. However, according the questionnaire, the students think that the grammar learning seems neglected. It can be seen from the following table as follows:

Table 1. The students' questionnaire on the development of language skills and components

\begin{tabular}{|l|c|c|c|c|c|c|}
\hline \multirow{2}{*}{ Statement } & \multicolumn{5}{|c|}{ Likert Scale } \\
\cline { 2 - 6 } & SA & A & NS & D & SD \\
\hline Language skills and components & $20 \%$ & $48 \%$ & $23 \%$ & $9 \%$ & $0 \%$ \\
\hline $\begin{array}{c}\text { 1. Project work helps me to improve } \\
\text { my listening skills. }\end{array}$ & $32 \%$ & $50 \%$ & $7 \%$ & $9 \%$ & $2 \%$ \\
\hline $\begin{array}{c}\text { 2. Project work helps me to improve } \\
\text { my reading skills. }\end{array}$ & $39 \%$ & $50 \%$ & $7 \%$ & $2 \%$ & $2 \%$ \\
\hline $\begin{array}{c}\text { 3. Project work helps me to improve } \\
\text { my speaking skills. }\end{array}$ & $32 \%$ & $57 \%$ & $11 \%$ & $0 \%$ & $0 \%$ \\
\hline $\begin{array}{c}\text { 4. Project work helps me to learn more } \\
\text { English words. }\end{array}$ & $32 \%$ & $57 \%$ & $11 \%$ & $5 \%$ & $5 \%$ \\
\hline $\begin{array}{c}\text { 5. Project work helps me to improve } \\
\text { my writing skills }\end{array}$ & $5 \%$ & $20 \%$ & $16 \%$ & $50 \%$ & $9 \%$ \\
\hline $\begin{array}{c}\text { 6. I learn grammar knowledge while } \\
\text { doing project work. }\end{array}$ & & & & \\
\hline
\end{tabular}

To support and cross check of the result of the questionnaire, the following are some comments from the students on the comment box in the questionnaire:

a. It's fun to have these projects overtimes because we can directly experience the application of English because what's grammar if we cannot use it?

b. Project-based learning makes us involved on using English as everyday language.

c. Project-based learning helps us develop our presentation skills since at the end of every project, we should be presenting it to the class and etc.

It was also found from the students' reflective reports which showed some activities that asked the students to use their English skills 
(Listening, speaking, reading, writing) in completing the projects. For example, in relation to speaking, they did interview as a means to gather data they needed with their classmates. They also practiced speaking as well as listening when they did the interview. Regarding the development of reading skills, the students had given the opportunity to develop their reading skills through a reading journal that was given by the teacher. Also, they learned new vocabularies through the process of doing the projects. While doing the projects, the students were also assisted to develop their writing skills as well, especially the writing fluency. The writing activities were often done when they did projects starting from the beginning up to the end. The students were often asked to note done step by step of the project. Also, they were some projects which they had to write a script. Besides, the reflective report played important roles in the development the students' writing skills. The report made them write something factual and authentic, they wrote fluently since they wrote something that they felt and experience it.

However, as the findings revealed that they do not think the teaching and learning activities through doing the projects helps them in learning grammar. Some of the students commented that they felt apart from learning grammar. It can be seen from the students' reflective report, they can write fluently but many of them do grammar mistakes. From the students' report, it was found that there was no grammar explanation from the teacher, in the beginning, or at the end of the study.

As the findings revealed that the implementation of ICT-supported PBL has helped the students to gain some self-development as well. There are some significant result dealing with the self-development such as increasing the students' motivation, creativity, teamwork skill, responsibility, active learners, and independency. The following was the result of the questionnaire regarding the self-development:

Table 2. The students' questionnaire on the self-development

\begin{tabular}{|l|c|c|c|c|c|}
\hline \multirow{2}{*}{ Statement } & \multicolumn{5}{|c|}{ Likert Scale } \\
\cline { 2 - 6 } & SA & A & NS & D & SD \\
\hline Self-development & \multicolumn{5}{|c|}{} \\
\hline 7. The projects increase my interest in & $23 \%$ & $45 \%$ & $14 \%$ & $9 \%$ & $9 \%$ \\
\hline
\end{tabular}




\begin{tabular}{|l|l|l|l|l|l|}
\hline learning English. & & & & & \\
\hline $\begin{array}{l}\text { 8. I can relate the project with real } \\
\text { life problems. }\end{array}$ & $30 \%$ & $52 \%$ & $7 \%$ & $9 \%$ & $2 \%$ \\
\hline $\begin{array}{l}\text { 9. Doing projects in the classroom } \\
\text { brings enjoyment. }\end{array}$ & $48 \%$ & $36 \%$ & $11 \%$ & $2 \%$ & $2 \%$ \\
\hline $\begin{array}{l}\text { 10. The projects require me to think } \\
\text { creatively. }\end{array}$ & $27 \%$ & $50 \%$ & $23 \%$ & $0 \%$ & $0 \%$ \\
\hline $\begin{array}{l}\text { 11. Project-based learning enhances } \\
\text { my team work skill. }\end{array}$ & $23 \%$ & $36 \%$ & $7 \%$ & $7 \%$ & $7 \%$ \\
\hline $\begin{array}{l}\text { 12. Project work helps me to enhance } \\
\text { the sense of responsibility. }\end{array}$ & $43 \%$ & $50 \%$ & $5 \%$ & $2 \%$ & $0 \%$ \\
\hline $\begin{array}{l}\text { 13. Project work helps me to be a } \\
\text { more active learner. }\end{array}$ & $16 \%$ & $52 \%$ & $32 \%$ & $0 \%$ & $0 \%$ \\
\hline $\begin{array}{l}\text { 14. Project work helps me to be a } \\
\text { more independent learner. }\end{array}$ & $47 \%$ & $16 \%$ & $30 \%$ & $7 \%$ & $0 \%$ \\
\hline
\end{tabular}

The students' motivation was promoted through two factors; fun and interesting activity and enjoyable classroom. The students' felt the projects were not boring since the projects were related to the teenager. They stated that making the video, for example, was a fun activity as well as they could see the benefit of the activity; video editing. The students also mentioned that they felt their English classroom now became enjoyable since they did not do paperwork but they did hands-on activities.

They mostly felt that the projects they brought some fun. They commented that they enjoyed doing the projects since they experienced something different from any English class activities they had ever had before. Instead of doing some paper works and exercises, in this class, they could create more fun and interesting projects. The following are some common comments taken from the students' report:

a. I like editing video and making the video in this project. I can learn more how to make the video because I am not really good at video editing.

b. I like this project because it improves my video editing skill 
c. The thing that I like from this project is we can learn how to make a video using a video editor.

Second, the project levels up their creativity. Most of the students agreed that the projects required the students' creativity. In order to get the project done, the students had to use their imagination a lot. The following are some common comments from the students' report regarding the creativity

a. The thing that I liked from this project is that we could use our own imagination.

b. What I like from this project is that we can create our own thing with our creativity.

c. What Catelyn likes from this project is she learns how to embrace her own creativity because this project required creativity.

As well the students agreed that the projects helped them to enhance their sense of responsibility. In PBL class, the students are given some tasks along with the deadlines and it makes the students have to really pay attention to the timeframe while working on the projects. Once they were irresponsible on the work given, the projects cannot be done on time. Here are some common comments from the students regarding the responsibility:

a. I learn how to respect others and be a responsible leader.

b. As always like the other English project I learned to be more responsible about my job.

c. I have learned how to have a good teamwork and how to manage my time so that I can finish all my tasks on time with a satisfying result.

The students developed their responsibility through the deadlines and workload of the projects. Meeting the deadlines made them try to be responsible for their learning. Then, the students also learned responsibility through sharing mutual goals. The projects could not be done alone so the students were put in a group meaning that they had to share the workload. It made them be responsible for their job in the group. Once they could not perform responsibility, the group was in trouble.

Third, doing project has enhanced their teamwork skills. As revealed in the questionnaire above that the items regarding on the 
collaborative skills were high in percentage. In doing the projects, they had to work with different peers in different projects. With this in mind, the students gradually learn how to work in a team. The following are some related comments regarding on the teamwork skill:

a. What I learn from this project is teamwork. Teamwork is very important because if you do it alone, you won't finish it on time. With three members each group, it is helpful. Besides teamwork, I also learn about bible verses and how to edit videos.

b. I also learned how to manage time and works in a group.

c. I have learned how to have a good teamwork and how to manage my time so that I can finish all my tasks on time with a satisfying result.

\section{DISCUSSION}

Evidently, There were three factors which led the students' have positive perceptions of ICT-Supported PBL in English teaching; (a) authentic learning situations, (b) student-centered activities, and c) the involvement of ICT.

The projects at the school under the study promote an authentic learning through the authenticity of learning situations as showed in the high percentage of the students' questionnaire on item 8, and 11. Authentic activities refer to activities designed to promote students' thinking and problem skills which are important in and outof-schools contexts and to foster learning to learn (Brown, 2000). There are some indicators why learning at the school under this study is categorized as authentic learning. The following is shown a table of element of authentic learning situation in doing the projects at the school under this study.

First, the projects' topics have real world relevance which gives them an opportunity to make sense of the usefulness of English as a communication tool. Project-based learning allows the students to link between what happens in their classroom to real-life opportunities in the outside world. They do not learn something they do not really understand but what they do in the classroom can be seen as a real problem in their life. These showed that the PBL approach links the students to connect English in the classroom to real-life situations 
unlike other conventional teaching and learning when they spend most of their time only on textbooks.

It also led them to build their creativity. In project-based learning, the students at the school under the study worked on projects which did not have one correct answer. The obvious reason was the nature of the projects gave the students opportunity to have different results so there is no single correct answer. They were free to have a different outcome as a final product or performance. As shown in synthetic culture project, the students had to make their own imaginary country and describe it through the booklet. Also, they had to create the culture of the country. That project led the students to think creatively by combining knowledge about country and culture with their innovative solutions in coming up with ideas. The students are free to explore themselves in completing the projects. To emphasize, a diversity of learning outcomes is really appreciated in project-based learning, the students can explore themselves as well as learn that there are so many possibilities to do the projects.

Second, the students also used English as the target language in completing the project. It helps them in situations that require the authentic use of language (Moss and Van Duzer, 1998). The nature of this project let the students use their four English skills which lead them to improve the four skills (listening, speaking, reading and grammar). It becomes understandable that PBL promotes the development of the students at the school under the study in terms of their language proficiency in listening, speaking, reading and writing. Not only the language skills were found to have enhanced, but also vocabulary skills were developed.

However, there was dissatisfaction from the students about the grammar learning. The students felt that the grammar learning was neglected. As noted from the questionnaire, the number of either strongly agree or agree was small for grammar part. To add, the student reflective report showed that there was a little evidence that showing the grammar teaching and learning activities. In PBL grammar should be taught integrated with other skills, but the teacher did not give any explanation about the grammar points either in the beginning or at the end of project work. It made the students could perform 
fluently but not with the accuracy. As shown in their reflective report writing, there were found some grammatical mistakes and it happens to the majority of the students.

As can be seen the focus of the English teaching at the school under this study is no longer teaching the students English by memorizing patterns or recalling information instead it is more on teaching the students how to learn English by experiencing it through giving the students opportunity to work on real-world topic or issues. In addition, project works are more on content learning rather than a specific language targets (Kloppenburg \& Baucus, 2004). By all means, the aim of the English learning through PBL is to create lifelong learners (Lee, 2002 as cited in Roza, 2011).

Third, collaborative work leads the authentic learning. The collaboration is seen as authentic learning because later on when they graduate from school they have to be able to work with other people. It is like given them the opportunity to work in a real workplace where they have to share ideas and negotiate the alternative solutions for every problem they face while doing the projects.

Student-centered activities were the second factor which brought the students has positive perceptions. There are three indicators why the school under this study has implemented student-centered activities. First, the collaboration in doing the project makes the classroom as student-centered. Through grouping activities, the students discussed and exchanged opinion to gain new ideas to get the projects done. The students not only worked together to achieve the goals but also they built interaction and socialized with their teammates. While working, interacting and socializing, they also developed important skills including brainstorming, planning, problem-solving, and evaluation.

In PBL, the students were forced to work in a real-life work setting where later on they have to work in a team hoping that they could see the complexity of working together. As they were engaged in their group work, they learned tolerance and open-mindedness as well as how to be discipline and responsible as they would be in a reallife. Later on, when they work in real-life, they will not get shocked since they have experienced working in a group. 
According to Crebert et. al. (2011), teamwork skills involve the combination of interactive, interpersonal, problem-solving and communication skills required by a group of people cooperatively sharing common work for a mutual goal. The nature of PBL requires collaborative work, it helps the students enhanced their teamwork skill. The first reason was that when they worked as a teammate, they did not only have to share ideas to the group but also had to respect the opinions of their group mates.

Through the collaborative work, the students' responsibility is also enhanced. As what the students have mentioned on their reflective report, in doing the projects they are put in a group. It was forced them to share the workload among the team members. Once one of the team was irresponsible with their part the whole member would get a problem. Therefore, it wakes up their sense of responsibility. The individual student in PBL has an important role in finishing the projects. Therefore, the students have to put effort to make it everything runs well as what teams expected. The students who involved in projects gain greater responsibility for their own learning than during more conventional classroom activities (Fried-Booth, 2002).

The second indicator is that the class ran with less domination from the teacher. The teacher does not involve too much in their process of completing the projects. As been mentioned in the students' report, the teacher helps them but he does not dictate them. The teacher's role is only as guidance and he gives suggestions. They are free to explore themselves and the teacher's role is only to facilitate and give a help when it is needed. PBL gives more opportunity for the students to discover their interest and talents.

The third indicator is the students' activeness. At the hand of completing the projects, the students have to find out solutions for every problem they face. The students mentioned that they confronted obstacles during the process; they struggled over the problems by the process of trial errors. Through the process of doing the project, they became active as problem solvers.

ICT-involvement was the third factor on the students' positivity towards PBL. The involvement of ICT in the process of 
teaching and learning drives the students to a more meaningful learning since technology has a wider spread and the students nowadays could not be separated from technology. To support the students' learning, the teacher also let them bring their gadgets such as laptops and mobile phone in the classroom to use them to research the topic on the internet. Jonassen and his colleagues (Jonassen, et al., 1999) applied a constructivist perspective to the use of technology in schools to create technology-based activities that support a meaningful learning.

Lately, ICT has become very important for all areas in business, politics, industrial as well as education. That is why the schools provide the students' soft skills related to ICTs. At the school under the study, ICT has emerged in teaching and learning process. As stated in the previous paragraph that the students are allowed to use gadgets in the classroom, it is because the technology is a part of the projects themselves. Computer technologies have played a supportive role in PBL. The students mostly did the projects which required ICT help. For instance, they produced a video as a final product in the video expose project. As what Moursund (2003) stated that the use of ICT has three new dimensions, they are: (1) ICT as an aid to carrying out the work, it is used to do presentation, performance or in a projects' products, (2) ICT is a part of the content of a project, and (3) ICT as the vehicle which helps the teachers to create a teaching and learning environment.

In this study, ICT has been in those dimensions and it helps the students to develop their creative projects. The students mentioned that by doing the projects, which mostly needed ICT involvement, they could learn something that they never did before or they knew little about it but then they could be better, they learn soft skills in computer-related. As what mostly the students wrote in their students report that they learn how to edit video. They were happy they could perform editing the video since it was fun. The involvement of computer technology makes the students be able to create such interesting projects through editing software such as Corel Draw, Microsoft video Maker and etc. It is really urgent for the educators to prepare their students to have soft-skills in computer technology or ICT since the job demands individuals who are knowledgeable in their 
fields and who are technologically-savvy. The involvement of the ICT in the projects was also one of the factors the students felt enjoyment in the English classroom and creativity.

\section{CONCLUSION}

To sum up, the implementation of PBL with ICT in the lately context brings positive learning atmosphere where the students participate in the process of constructing their knowledge and skills. There were three factors or causes which led the students' positive perceptions toward the implementation of ICT-supported PBL in English teaching. First is the authentic learning situation. Second, it applied the students-centeredness. Finally, the involvement of ICT made them perceive positive perceptions towards the implementation of ICT-supported PBL. It made sense because lately the students definitely involved with ICT in their daily lives. Though it seems flawless, mostly the students complained about the time, they thought that the time for developing the project was too short since they also overloaded with other works from other subjects. Likewise, there were some students felt that they were away from learning English grammar.

Meanwhile, there are two suggestions based on the findings of this study are given. The first, the teacher should consider grammar points in his teaching though his focus is upgrading the students' skills in communicating due to the fact that there were some students who felt unhappy because the grammar seems to be neglected in their English class. The second, teaching and learning activity is very complex since there are many factors involved. Many perspectives can be used to investigate the Project-Based Learning. That is why there is still a need for more research on the effects and effectiveness of PBL. It is needed not only as guidance in PBL instruction and the development of projects but also to get justification of PBL practices. To add, further research on the effectiveness of ICT used in PBL class should be conducted. How ICT is used and the impact on the students should be investigated. 


\section{REFERENCES}

Brown, D. H. (2000). Principles of language learning \& teaching. (4th ed.). New York: Longman. (pp. 49-58)

Crebert, G, Patrick, C-J, Cragnolini, V, Smith, C, Worsfold, K \& Webb, F (2011), Teamwork skills toolkit. http://www.griffith.edu.au/ gihe/resources-support/graduateattributes(accessed 30 May, 2016).

Fried-Booth, D.L. (2002). Project Work, Oxford: Oxford University Press.

Jonassen, D. H. (1999). Learning with technology: A constructivist perspective. Upper Saddle River, NJ: Prentice Hall.

Kloppenborg, T.J., \& Baucus , M.S. (2004). Project management in local nonprofit organizations: Engaging students in problembased learning . Journal of Management Education, 28, 610-630.

Moursund, David. (2003). Project Based Learning using Information Technology. International Society for Technology in Education. Eugene. Oregano.

Moss, D., \& Van Duzer, C. (1998). Project-Based Learning for Adult English Language Learners.

Roza, A. (2011). Project-Based Learning in the Algerian Secondary School Syllabuses and textbooks (Unpublished Dissertation). Memmeri University of Tizi-Ouzou. Alegarian.

Stake, R. E. (n.d.). Retrieved 6 10, 2016, from https: / / www.sfu.ca/ palys/Stake2003-CaseStudies.pdf 